\title{
Perspectives
}

\section{Storyweavers: \\ Holistic Education for ESL/EFL Learners ${ }^{1}$}

\section{Virginia L. Sauvé}

In an L2 classroom that is taught from heart to heart, story takes on a different role than in the classroom that is primarily about the conveying of information and the development of linguistic skills. In the latter classroom, stories have been about reading comprehension and the acquisition of new vocabulary. In a classroom where the teacher recognizes education as the drawing forth of the individual and the shaping of a community acting on the world, story assumes a central role. In this article the author explores the realm of story in such a classroom and shares many of her own stories. When story is the medium of learning rather than just the end thereof, we come to see that the learners' real needs are much greater than vocabulary, pronunciation, and grammar. We also see that in such a classroom, community emerges.

Dans une salle de classe ALS où l'enseignement et l'apprentissage se font dans un contexte ouvert, personnalisé et axé sur les émotions, le récit ne joue pas le même rôle que dans une classe où l'on se penche sur la transmission d'information et le développement d'habiletés linguistiques. Dans ces dernières, l'étude du récit se fait dans le but de travailler la compréhension écrite et l'acquisition de vocabulaire. Par contre, dans une salle de classe où l'enseignant interprète l'éducation comme un moyen visant l'épanouissement de l'étudiant et la création d'une communauté évoluant dans le monde, le récit assume un rôle central. Dans cet article, l'auteure étudie l'envergure du récit dans une telle salle de classe et partage plusieurs de ses propres récits. Quand le récit sert de médium à l'apprentissage plutôt que tout simplement sa fin, on en vient à comprendre que les besoins véritables des étudiants vont bien au-delà du lexique, de la prononciation et de la grammaire. De plus, dans un tel contexte, on est témoin de l'émergence d'une communauté.

Let us consider for a moment how we get to know one another when first we meet. Imagine that you have just been introduced to someone at a party and after the basic questions discover that you have a lot in common. What do you do? You share stories. One person starts and the other takes the cue and adds a story of her own. You laugh, commiserate, share concerns, reflect on decisions, and in so doing you come to know one another. In sharing our 
stories we come not only to know about the other persons, but to understand what makes them tick, to understand why they say and do what they say and do. How, I ask you, can I teach anyone anything important if I do not really know them? And how can they totally trust my words, if they do not know me? I believe that an authentic educator is a weaver of stories, a storyweaver, who skillfully recognizes the beauty of each strand of human experience embodied in a story and who knows just how to place each strand as together we weave lives of meaning in and outside of our classrooms.

As teachers, what is it that we do in a classroom? We could say that we teach the skills that enable a person to be in English, that we convey valuable information about the English language and the culture in which it is spoken, and to an extent that would be true. But it is my belief that a more relevant question might be to ask, "Who are we in the ESL classroom?" Over the years I have learned that what people remember most from their experiences in the classroom are the relationships they had with the teacher and other learners and how those relationships left them feeling about themselves and the world around them.

I recall having a Cuban student in my classroom just after Castro emptied out his prisons by allowing the inmates to go to Florida if they so wished. This was a troublesome young man. He appeared to be arrogant and insensitive to the needs and feelings of others in the classroom. He had a tendency to dominate every interaction, and it was not hard to see that the other students were fast reaching a point of not wanting him to open his mouth. Also in the classroom was an old man-I no longer remember which Eastern European country he was from-who seemed to be mentally absent from the classroom. He never spoke and had a far-off look in his eyes most of the time. He showed no signs of learning anything. Raul demanded attention and Ilya needed it, so I took a chance and asked Raul to spend some time with Ilya and try to get him talking. Proudly, Raul said he would help and, at coffee time, I saw the two sitting on a bench outside speaking with great animation. (They had to speak with their hands and bodies because Ilya's knowledge of English was minimal to say the least!) I was delighted and couldn't wait to find out what had happened. At noon I asked Raul how it had gone, and he too was excited. By asking him a few questions, Raul had discovered that they shared a common love of music. Both played the guitar. They were often seen together after that day. Ilya began to speak up more in the classroom. His connection with Raul had helped him to connect with the classroom as a whole, and Raul continued to take pride in facilitating Ilya's emergence into the world of English learning. I don't think it was just my imagination that he seemed much less of a nuisance to everyone else. He had found a valued role, and he did it by sharing stories with an old man with whom, from all obvious perspectives, no one could have expected he would have had anything in common. 
I believe that, as educators, we are at best storyweavers who recognize that in the classroom experience human beings are learning to discover and claim their highest selves; that they, and we, are learning what it means to live in community with one another; and that we are creating a vision of possibility for a world in challenging times. As you read some of my stories and ideas, your own will surface, and I invite you to let this be a time of reflecting on the stories in your teaching and learning practice, stories whose inherent truths can inform your own future practice as an educator, one who draws forth the potential of her or his students.

For Canada's First Nations' peoples, the role of story is solid and valued. Some years ago the Saskatchewan Council for Education of non-English Speakers (SCENES) had a conference in which they invited a Native storyteller to speak after lunch. Never have I experienced such a powerful storyteller. He spoke from the heart, in his own words, and his mastery of the audience was total. We laughed, we cried, and we got angry. At one point many of us felt that it was just too much, and we were ready to walk out the door. But he knew just how far he could push us, and at that point he made us laugh, and once again we were in his hands.

A story is a whole experience. It has a beginning and an ending. Although we often forget theories and ideas, we tend to remember stories because they connect with something inside us: emotions, our own experiences, our own dreams. When we hear a good story it becomes woven into our own library of stories, altering not only the shape of the other's story in the journey, but that of our stories as well. The second-language learner comes into our classrooms with stories. In many classrooms, these stories seldom if ever have a chance to be told. I believe that the wise teacher understands the need for her students to tell some of the significant stories of their lives, and in doing so to claim once again the dignity of being human and unique as we walk on the land and make our imprint on it. I do not see this as a teaching technique because to do so is to trivialize the relationship we have with our stories. Storytelling is more a natural sharing that comes out of the relationship we cultivate with learners and among learners. When the individuals in a classroom feel safe to be who they are, with all their fears, doubts, and questions, as well as their achievements, failures, and dreams, then and only then can they move from the stories of their past to understanding and taking control of their present and their future. And in this new land their future is also our future. We too are participants in the ongoing drama of creating a multicultural society and a peaceful, healthy planet for us all. As an educator I can choose to be a weaver of stories, past, present, and future, with those learners who have entrusted themselves to my classroom.

I would like to tell a story of a woman I shall call Jill. She is a sewing instructor in a large garment factory, a job she has held for over 30 years. She is well liked by the operators and the management alike, because she gets 
things done, quietly but surely. When the supervisors won't listen to the concerns of the operators, they turn to Jill, whom they can address in Chinese, the dominant language of the plant, and in whom they have confidence. If she can help them, she will, without making waves. When the supervisors or managers have an extra job to be done, they ask Jill because they know she will not turn them down regardless of how stressful it may be for her to get everything she needs to do done. These extras are not a part of her job description. Other instructors do not do them. But Jill understands only too well the terrible boredom of the operator's job for she did it for many years, and perhaps more important, she knows the soul-numbing effect of the supervisors' condescending remarks, having endured them throughout her own employment as an operator.

For years Jill has attended English classes at night, as well as EWP (English in the Work Place) classes in the plant. In spite of those classes and her determined effort to learn the language, she had not made much progress. Pronunciation continued to be a problem for her, as did her ability to phrase things in English syntax. She continued to think in Chinese, and largely still does. But because of her dedication to the plant in which she works, her employer sends her weekly to special communication classes with other administrative personnel to improve her overall communication in English.

About six months ago something significant happened and her learning took off. She entered the classroom that day looking tense and unhappy. I asked her if something were wrong, and she told me how upset she was about the way one supervisor always talked to her. She especially disliked the fact that this woman shook her finger under her nose and spoke to her as if she were a stupid child. I asked her what she would like to do about it. She looked surprised and said she would like it to stop. Again I asked, "But what would you like to do about it?" This time she said, "I would like to tell her not to talk to me like that. I would like to ask her to speak to me politely when she wants me to do something and to not shake her finger in my face." Then I asked Jill if she could say this to the supervisor. She said she didn't think she could, that when she was nervous her English wasn't very good. I asked if she would like to write a letter. She looked happy and said that she would, if I would help her to do so. She then sat down and proceeded to write down her ideas as best she could. I corrected the letter. She then rewrote it and delivered it to the woman and waited right there while she read it, an act of great courage from where I sat. The supervisor was stunned and apologized to Jill. Jill came back to the classroom with the biggest smile on her face, and I knew that something major had shifted for her that day. Today she still struggles with grammar, but she has a totally different sense of self. She knows she can communicate. She now knows she can learn, and she is learning. She knows she is valuable. Now she helps other people in the group 
who are struggling, and each time she does this she seems a little stronger. Even her face looks different, as if she has relaxed muscles held in tension for years of swallowing her humiliation and anger.

What does this story tell us about the ESL classroom? Well, it tells us that what learners need most is not always the traditional elements of the L2 classroom. In Jill's case, what she needed most was self-confidence, and the route to that end was in experiencing success in standing up for her dignity. My role was simply to support this as best I could, to ask her questions to help her clarify what she was ready (or not ready) to do, and then to bear witness to her success and acknowledge it. In 30 years of doing adult education, I have come to a place where I see accountability (the opposite of blame) as one of the most valuable concepts for people to learn in their lives. Jill made a decision to change 30 years of feeling humiliated by drawing some boundaries around how she would be treated in future. In the past six months that supervisor has not once treated her in a demeaning fashion. Jill's decision not only affected her life, but it also forced that woman to see her as a person. If enough people in the supervisor's life do the same thing, there is no doubt in my mind that she too will change as a result. Learning involves making shifts that enable us to be more in alignment with our true selves, our highest selves.

When we enable a person to learn something that will change their lives for the better, we can trust that this will have ramifications not unlike the ripples that expand outward when one drops a pebble into a still pond. Here is another story from the workplace that demonstrates this process of interconnectedness. Shandra is a housekeeper in an urban hospital. Of Hindi heritage, she comes from a small South American country. Shandra attended a four-day workshop I conducted for her department about three years ago. I remember her because she seemed to isolate herself from others by her perfectionism and her assumption that others should see the world the way she did. She was stuck in blame.

How surprised I was a few months ago when I returned to her hospital to facilitate a communications workshop. I noticed that she was much more fluid in her relating to others, but I was nonetheless unprepared for what she shared with me at the coffee break. She took me aside and said, "Virginia, I just wanted to thank you for that workshop you did three years ago. It changed my life." Needless to say, she had my complete attention now. I asked her to explain. She said,

It was that idea of accountability. I went home and I thought a lot about that. My husband and I had not been getting along too well. I was always nagging him to do "his jobs" and he was always upset with me for nagging him. 
One day I looked at the garbage overflowing and I thought about what you had said about accountability. When I had told you about the soiled utility room in the hospital, you had asked me if that was not something I could deal with myself and you were right. I could. There was this garbage overflowing and I thought to myself, "I can empty that." I did, and I felt much better. So at home I started doing more and more of the little things around the house that I used to wait for my husband to do. I didn't say anything. I just did them. After about three months, my husband noticed and he spoke differently to me. He said, "You don't nag me anymore. I feel so much better." We get along a lot better now."

Then Shandra decided that if this idea worked at home, maybe it would work at work as well. "One day, the perfect opportunity arose. There was this one nurse that no one liked. She treated the housekeeping staff like dirt. If we missed something," Shandra told me,

Instead of quietly reminding us, she would yell at us in front of the doctors, the other nurses, patients, visitors, anybody. It was so embarrassing. She did it to me this day. I had gone in to clean a patient's bathroom, but she was using it and I thought I'd come back later, but we got really busy with discharge rooms and I forgot. The nurse screamed at me, waving her arms around, and I remembered what you had said. I didn't say anything at that moment. I waited until she went into the Med Room and I followed her in. I said, "Mrs. Smith, I need to talk to you. I don't mind you correcting me when I make a mistake but could you please do so privately? It is really embarrassing when you yell at me in front of other people." The nurse looked flustered and apologized.

Shandra finished her story by saying, "Today, Virginia, that nurse is a changed nurse!" A huge smile on her face showed me the pride, delight, and strength she had gained from shifting from blame to accountability. By this point, several other housekeepers had come back into the room and heard her story. One said, "I know who you mean! She treats everyone differently now. It is as if she sees us for the first time!"

And here we have it-the cry of us all to be recognized! The chronic complaint of so many immigrant workers going into service jobs is that of feeling invisible. Most accept this as the price of leaving behind a country and culture of which they were a part, in which they felt respected for who they were. But a few, like Shandra and Jill, realize that they do not have to sacrifice their dignity just to earn a living in Canada. And when they can see the power in taking accountability for expecting to be treated with respect, rather than just complaining about it, everything shifts. A male family member saw his wife in a different light and began to appreciate her more than he had in his own country. A Canadian nurse was forced to see a housekeeper 
for the first time as a person rather than a functionary, and this changed how she treated all the others in that role. And in both Jill's and Shandra's situations, their actions were triggered by an idea that they learned in a classroom: accountability.

Accountability is the opposite of blame. When we choose to be accountable rather than to blame others for our problems, we are acting out of whatever power we have in a given situation to make it better for ourselves. Blame is most often irrelevant. It does not matter who started it or who did what. What matters is what can be done to change the situation for the better. Can you imagine what might happen in Palestine or many other situations of world conflict if the combatants could step outside of blame and into accountability? For that matter, what might happen in our lives if we got unstuck from those we blame for our problems and instead looked for what we could do to make things better for ourselves, now, today, as we are?

Years ago I was blessed to participate in a two-week Train the Trainers event with Virginia Satir, a well-known author, psychologist, and teacher. One of the teachings that has stuck in my mind from that event was the simple idea that everyone does what is logical to him or her in any given situation, and if we do not understand it, it is because we don't have all the information. That idea went on like a light bulb in my mind. Suddenly I felt that I understood what made forgiveness possible. If I could just see the world as the other saw it, how could I possibly blame and be angry with that person? I know that I act in ways that are logical to me at the time, even if later I have cause to regret my words or actions. If this is true for me, why would it not be so for others? Blame is a heavy burden to carry around, and goodness knows, our refugee learners and many of our immigrant learners have much to be angry about. They have every right to feel angry about things that happened to them in their own countries and things that have happened since they settled in Canada. But how does anger enable their lives if they get stuck in those feelings, however justified they are?

Buddhism teaches us to live in the moment. For that matter, so did Jesus, and so do most of the world's great religions. There is such wisdom in this idea. To let go of the past and not worry about the future is to free all our energy for living this precious moment. To me these ideas have so much to offer us in ESL or EFL, or in any classroom that is about human development. When we teach language, we are making decisions at all times:

- What words do we teach and what words do we omit?

-Who has the power in the classroom, the teacher or the learner, or both? And that being the case, how is it shared?

- How do we engage what is to be learned? Is there a tight curriculum to be followed? Do I the teacher decide what is taught, or does the process of learning emerge more naturally from being present to what is going on in the moment? 
The storyweaver listens carefully for the learners' stories as they are offered and makes space for their telling, supporting the tellers with whatever language they need to express themselves, ask their questions, reclaim their lost dignity, and take charge of their lives. Magic happens in the classroom when that space and that trust are there. I remember going into a class of seniors some years ago to do some research and wanting to give something back to this group of men and women, so I offered to do a Medicine Bag workshop, an idea I had gained from Ruth Smiley, a former Saskatchewan educator working in popular theater. She and a colleague had written a book called Story Circles that was published by the Saskatchewan Teachers' Federation, and the Medicine Bag stories were one idea in that book. I worried that these beginning-level seniors would not have sufficient English to tell their stories, but as always, nothing is more motivating than the desire to tell our stories and be acknowledged in them, to be recognized and seen for the essence of who we really are. I had put a red mitten in my bag that day, and an old Chinese man picked up the mitten and began talking about his childhood in China. Sometimes he would laugh and at other times he had tears in his eyes; I don't fully understand yet how we knew what he was trying to say, as his vocabulary was small and his English grammar virtually nonexistent, but understand we did. Other Chinese speakers in the group helped him find key words he could not find, and when he finished, he sighed contentedly, and in his eyes and halting words we saw the journey of this man's life from a child in China who had worn red mittens knitted by his grandmother, to a man recognized and respected for his achievements in his country, to a man now struggling with old age and an environment he could not yet comprehend, and that certainly did not comprehend him.

I think of another senior citizen, this one in Winnipeg, a Filipino woman who picked up a blue candle from the bag and told her story of putting a candle in the window every night to guide her husband home when the Japanese soldiers came and took him away to work as a porter during the occupation of her country. For three months she put a candle in the window every night and prayed for his safe return. Finally, he did come home, hungry, exhausted, and demeaned by his captors but safe for the moment. In her telling of this story, we all cried with her as she remembered her fear and her pain, and we saw more than her experience. We saw the experience of the Filipino people and of occupied peoples everywhere. She learned the words to tell her story, and we learned a lot about courage and faith and the human ability to survive.

What does it take for a teacher to be a storyweaver? First and foremost, it takes the willingness to set aside one's ego and be fully present to the learners in the classroom. It is not at all easy. We have all had students who pushed our buttons. Perhaps they were disrespectful, or loud, or dominat- 
ing, or uncooperative, or critical. But how often do we take the time to reflect on what it is inside us that creates these buttons for others to push? Our reaction to these students is never about them; it is about us. The student who is disrespectful or critical pushes our insecurity button. The one who is loud, dominating, or uncooperative pushes our power button, our need to be in control. When we begin to react from these places, we are not at our best, and we are creating in the classroom feelings and situations that are not at all conducive to good educational practice.

How do we set aside the ego and take account of our own reactions inwardly before they manifest and create problems in our teaching? It is a daunting task, but far from impossible. I have found it helpful to learn the art of twin attention. You are listening to the other person who says something that pushes a button or calls forth an unfinished memory somewhere. When you are listening with twin attention, you continue to be fully present to the other, but at the same time you acknowledge to yourself that something is going on inside yourself that bears attention; you mentally set it aside and determine to work on it later. When you are no longer with that individual, you sit down with your journal and start exploring the emotion, or the memory, and the reaction you had when that was triggered. You work with it as much as you can or until it no longer has power over you. Slowly, slowly, you regain those pieces of yourself that have been taken, or given, away in the past. It is a work of inner healing. Native people call it soul retrieval.

The storyweaver is also a healer. As an adult educator I have worked not only with immigrant learners, but also with inmates, women on social assistance, university students, and workers in a variety of workplaces. One thing that is common to all of those contexts is the wounds that each of us carry around, unwittingly allowing them to misdirect our good intentions and damage our relationships with others and with ourselves. The child who has been abused can become an abuser of others. The child who has been ignored can become the loudmouth joker. The person whose personal pain has been too long ignored can become the chronic complainer. When I see a person consistently behaving in dysfunctional ways, I see a person who is hurting deeply inside and is stuck in behaviors that work to ensure that hurt will continue until he recognizes the source of his pain and allows it to transform. I cannot change that person, but if I care enough and am patient enough, I may be able to ask the question or make the observation that enables that individual to see, for just an instant, the consequences of his choices, and to see also that there are alternative choices to be made.

We have all had the experience of looking at another person and seeing the obvious. If only she would do such-and-such, her problems would be largely resolved. But she does not see it, and my telling her only drives her further into the kind of defensiveness that makes it even harder to see for 
herself. The wise witness loves the person inside the form, no matter how dysfunctional that form has become. The wise witness honors that individual's right to make the choices that define her own life. The wise witness also sees the inherent power this person has to make new choices and recreate her experience of life. That is having faith and hope as our guiding perspectives. As Virginia Satir said, each person does what is logical to him or her. Each one sees the picture as life has thus far painted it for that person. We may see a much broader picture than does the learner, and if we can paint that picture such that the learner can see himself in it, then we have opened the way of possibility for that learner to change when ready to do so.

The woundedness of adult learners, and children for that matter, is ignored at great risk, for it is our wounds that cause us to get stuck and unable to grow into our potential. When I do the Medicine Bag stories in a group where people know one another, where the level of trust is high, some wonderful things have happened. I recall one group of women in a job training program some years ago. The first time we did this exercise, people dug deep to share stories that had marked them in a significant way. One woman, through tears of shame and anger, told of a doctor molesting her in a hospital when she had first come here. We were the first people she had ever told, and she trusted us to tell no one else. The doctor was a person who spoke her language. At the time this happened, she did not speak any English and she dared not tell her husband as he would have killed the man, and she did not want to risk losing her husband. Another woman, whom everyone had seen for her great strength, was herself amazed when, in tears, she spoke of her guilt as a child of 8 when she was unable to save two small children who had been entrusted to her care when a flash flood roared through a canyon and sent her scurrying up a tree to safety. Not everyone took this kind of risk, but all of us were deeply moved by those who did, and the group became close after that. They had shared and been entrusted with their darkest secrets, and it changed the relationship they enjoyed with one another. When it came time to find work, they went out of their way to pass on leads to one another, even if it meant more competition for a job they wanted themselves. The stories enabled a community to emerge out of a group of strangers.

In my experience, when there is a sense of community, everyone's learning is enhanced. The teacher's job is easier, and so is the learners'. It helps them to ask questions without fear of being embarrassed by their ignorance or seeming slowness to catch on to new ideas. When the trust is there they can take the risks they need to take to extend themselves beyond where they are to where they want to go. They can learn from one another's mistakes, and they can share their resources for the benefit of all. When people share their stories and are acknowledged for them, they come to feel that they are acceptable as they are, without conditions. They can let go of the defenses 
they have built up to protect themselves, defenses that more often than not cause them problems in relating to others.

I have also learned that it is important to be inclusive in storywork. In the job training program referred to above, I had not included the other instructors in the program in this exercise, and as a result they were not part of the circle of trust that resulted. Similarly, journaling has become a popular feature of many L2 classrooms in the past 10-15 years. Students often tell stories in their journals, and although this may enhance the relationship between the student and the teacher, it can backfire in terms of creating problems in the classroom, especially if the student shares problems he is having with another student. Openness is consistent with this kind of work. Although I still do journal work when it seems appropriate, I encourage people not to write anything that they would not want everyone to see. There is also someone who picks up the journal when the owner is not around and reads it. And there are other students who share their journals, so you do not want to write anything you would not want everyone to see either.

And this kind of work is not without risk. One of the saddest experiences I have had as a teacher happened the night I arrived in Chunchon, South Korea for a banquet held in my honor with a group of Korean teachers I had taught the summer before. I noticed that everyone was there except for one woman with whom I had become close. At the end of the summer she had written in her journal: "I came to Canada to improve my English but I have found my Self. I thanks you very, very much." When I noticed her absence at the banquet, I leaned over to the host and asked where she was. He looked serious and said he would tell me later. So I waited until the banquet was over and we were driving home and asked again. He said that she had gone into a psychiatric hospital for treatment. I was stunned. She had seemed shy, and I knew she came from an oppressive, traditional household where Father would still set the marriage and determine how his daughter's life would be until she was married. But she seemed like a lovely, healthy individual to me. How could this have happened? My host explained that Canada had been unsettling to her. She saw how I lived my life and how Canadian women in general lived, and she was no longer content to live without freedom. When she began to confront her father, her family life began to unravel and she could not take it. I sat quietly in the car, trying to take all this in. I remembered our conversations and the contents of her journal and felt responsible for her having challenged the old Korean ways. What right did I have to think I knew anything at all about her life and what was good for her? My rationale mind-or was it my rationalizing mind?said that she was simply a victim of intercultural collision. But my heart bled for her, and I still wonder how I might have responded differently to her.

One of the dangers inherent in our work as English teachers to speakers of other languages is the temptation to assume that our values are a justified, 
unquestioned part of the package. Culture and language are all wrapped up in the same thin tissue. The way I address the students, the way I hold my body and move my eyes, the words I choose to teach, and how I choose to teach them are all part of my culture. To the extent that I am aware of my culture, I can compensate for any unwanted challenges these may bring, but the fact is that I am more often than not completely unaware.

When I taught my first group of Korean teachers, I came home after Day 1 absolutely exhausted and wondering what I had gotten myself into. I was used to teaching a multicultural group where people spoke many different languages, and it had not occurred to me that this group would be so different. It was a day of trying everything I knew to get them talking and them sitting there obviously finding me peculiar. When I asked open-ended questions, no one would answer, so I would then direct my question to the face that appeared to be most open to the possibility of answering, in most instances, a young woman in the group. She was delighted to be asked and had fluent English compared with the rest of the group. I was surprised after lunch when she returned to the classroom with tears on her face. She told me later that she had been reprimanded for causing the elders to lose face when she answered my questions. She also told me that they did not understand why I was not asking my questions in the right order, namely, from senior male down through the men and on to senior woman and down.

It was only at that moment that I realized the answer to a question I had asked myself at the airport when we picked them up. I had wondered at the time why they had given me a list of names organized with all the men at the top and the six women at the bottom. The names were not alphabetized, which would have been our way. Now I looked at the list and saw that they had given me the code by which I could address them. Age and status determined where one was placed on the list. If one had graduated from one of the top universities and/or was in an administrative job, then one's name was high on the list. The young woman who had been answering all my questions was at the bottom of the list. I had just been given my first lesson in the concept of face, which is so important in Asia.

As successive years of Korean teachers came, of course I adapted, as did they, and the coordinator of this year's program will not face the situation I did because these teachers will have been briefed by their predecessors, as this coordinator will have been briefed by her predecessor. And as group after group of these teachers goes back to Korea, I have no doubt that they will share their stories of Canada with their students, shaping their perceptions of our country and its people. Some of those students will come to see for themselves. And some will even move here and raise children who will be the next generation of Canadians, giving their gifts and talents to this country. 
You and I make a difference in our classrooms, as each and every student can and should make a difference in that same classroom. This takes us to the notion of curriculum. A curriculum is normally understood to be, primarily, a teacher's guide to what is to be taught in a particular course of studies. It includes goals, objectives, and resources to be used. I have no problem whatsoever with a teaching plan, as long as that plan remains open, flexible, and aware that there is much we do not know about the learners we will be teaching. To assume that each student or each group is the same is simply false. It is this assumption that leads us to accept the casualties of the classroom. Those are the students who couldn't learn what we were teaching or couldn't keep up. Typically such students are dealt with by having them repeat the course, or in ESL stay at the same level. At one institution where I taught for several years, they were referred to in Continuing Education as the terminal zeroes. Richard Darville, an adult educator who taught in Vancouver for many years before taking an academic position in Ottawa, wrote a lovely book called It Takes Two to Fail. (You won't be able to find this book unless you find a friend or a library that has it because it has for years been out of print.) I like it because it acknowledges that when students fail to learn, we as teachers have also failed to teach.

The healthy curriculum is a living, breathing curriculum that begins with the assumption that we don't have all the information and that we will gradually get more information as we get to know the individuals in our class and they get to know us. Out of those interactions a good curriculum will change and grow. I have come to view a healthy curriculum plan as a set of starting points that in no way predetermines the finishing place of a curriculum in action.

I work with a group of teachers who have been teaching in the same garment factory for 15 years. We have developed two detailed curricula over the years, but no one looks at either anymore. However, if you want to know what we teach, it is well documented in two annual reports. In each we have class summaries documenting the kinds of learning that took place, sample materials from each class, and most valued, the anecdotes collected from each of the teachers that show what a difference learning makes in the lives of the learners. These anecdotes also give the reader a sense of what life is like for teachers and learners in the class. The humorous stories are particularly valued. One of my students in a Saturday morning class brought pot-stickers that she had made earlier that morning. They smelled delicious, and as I took my first bite, one of the students asked her what she put in them. She replied, "Pork and garbage." I stopped in mid-bite and asked her to repeat it. She did so, and the whole class laughed heartily. She looked confused and the woman who had asked the questions said to me, "I think she means cabbage." Then the cook laughed too, and now, if anyone in the class mentions cabbage, or garbage, or pot-stickers, we all laugh. That incident has become 
part of our tapestry, part of what makes us special as a group. So is the healing wand given me by one of the women who was a healer in Vietnam. She came to my house one day when I was ill and worked on me with this instrument, insisting that I keep it and use it whenever I needed it. So is the green planter I gave her when she needed it and I did not. So is the trip to the Devonian Gardens we made last year for our closing party, a party to which half of the garment factory came along with their families. I wondered why the parking lot was full of cars that morning. The word was out. People not in the classes are now asking where we are going this year.

So how do we decide in this EWP program what to teach? Mostly we work it out with the students as we go. We decide on a set of intents and priorities every five months, and we evaluate it at the end, not so we can judge ourselves or anyone else if we do not succeed in achieving those priorities, but so that we can explain why we changed direction if we did so. The company has come to trust us and to see us as part of the staff at the plant. They pass on bulletins to explain to students, and we pass on concerns when we hear them. Our teachers are regular servers at the Christmas dinner and the Children's Christmas Party. We proudly wear the company T-shirts and carry the special bags we have been given with the company logo on them. At the 10-year anniversary of the English program, one of our teachers worked with her students to prepare a wonderful video of the program with images from the 10 years we had been together. That video was like a patchwork quilt of treasures, and each square on the quilt has a story behind it.

One of my Saturday morning students keeps asking me why I still teach that class. She knows I am doing many of other things, and lately I have been traveling and doing new kinds of work that have nothing to do with ESL per se. Each time I tell her: because I enjoy it! And although this is true, it is more than that. This group of nine women keep me honest. They are sewing machine operators. Their lives are difficult. Each one says that if there is such a thing as reincarnation, she wants to be a man in the next life because it is too hard to be a woman. Their stories have become a part of me, even as mine have become a part of them. We are, all of us, storyweavers.

\section{Note}

${ }^{1}$ This article was originally given as a plenary paper at the TESL Canada 2002 Conference in Regina in May 2002.

\section{The Author}

Virginia Sauvé is a consultant living in Edmonton. She is best known for her ideas in participatory and workplace education. She is the author of the Voices and Visions books published for teachers by Oxford University Press. 